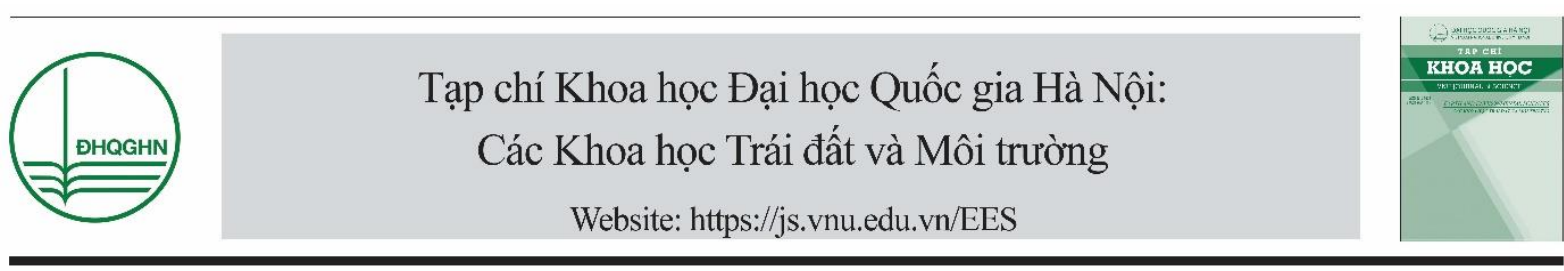

\title{
Khả năng chịu acid, kháng và hấp thụ nhôm của nấm mốc phân lập từ đất trồng chè vùng Tân Cương, Thái Nguyên
}

\author{
Ngô Thị Tường Châu ${ }^{1, *}$, Nguyễn Thị Mai Lương ${ }^{2}$, \\ Phùng Thị Ngọc Mai ${ }^{1}$, Đào Văn Huy ${ }^{3}$, Lê Văn Thiện ${ }^{1}$ \\ ${ }^{I}$ Truòng Đại học Khoa học Tự nhiên, ĐHQGHN, 334 Nguyễn Trãi, Thanh Xuân, Hà Nội, Việt Nam \\ ${ }^{2}$ Truoòng Đại học Lâm Nghiệp, Xuân Mai, Churong Mỹ, Hà Nội, Việt Nam \\ ${ }^{3}$ Viện Đảm bảo Chất lượng Giáo dục, ĐHQGHN, 144 Xuân Thuỷ, Hà Nội, Việt Nam \\ Nhận ngày 31 tháng 10 năm 2018 \\ Chỉnh sửa ngày 13 tháng 12 năm 2018; Chấp nhận đăng ngày 17 tháng 12 năm 2018
}

\begin{abstract}
Tóm tắt: Từ các mẫu đất trồng chè vùng Tân Cương, Thái Nguyên, 16 chủng nấm mốc có khả năng chịu acid và kháng nhôm đã được phân lập trên môi trường Hansen thạch đĩa $(\mathrm{pH} 3,0)$ chứa nhôm với nồng độ $100 \mathrm{mgL}^{-1}$. Trong đó, hai chủng nấm mốc ký hiệu $\mathrm{F} 8$ và $\mathrm{F} 13$ có thể phát triển tốt trên môi trường Hansen thạch đĩa $(\mathrm{pH} 3,0)$ chứa nhôm với nồng độ lên đến $700 \mathrm{mgL}^{-1}$. Các phân tích về đặc điểm hình thái và trình tự nucleotide của các gen $28 \mathrm{~S}$ rDNA đã chỉ ra rằng chủng F8 thuộc loài Eupenicillium javanicum và chủng F13 thuộc loài Penicillium variabile. Các khảo sát tiếp theo đã cho thấy cả hai chủng nấm mốc $\mathrm{F} 8$ và $\mathrm{F} 13$ có thể phát triển tốt trong môi trường Hansen dịch thể chứa nhôm với nồng độ $100 \mathrm{mgL}^{-1}$ tại các giá trị $\mathrm{pH}$ từ $2,2-5,0$ và với nồng độ $500-2.000 \mathrm{mgL}^{-1}$ tại $\mathrm{pH} 2,4$. Sau 7 ngày nuôi cấy trên máy lắc ổn nhiệt tại $30^{\circ} \mathrm{C}, 150$ vòng/phút, hiệu suất hấp thụ nhôm từ môi trường Hansen dịch thể chứa nhôm với nồng độ $2.000 \mathrm{mgL}^{-1}$ (pH 2,4 ) của chủng $\mathrm{F} 8$ đạt $92,06 \%$ và chủng $\mathrm{F} 13$ đạt $86,88 \%$. Vì vậy, hai chủng Eupenicillium javanicum $\mathrm{F} 8$ và Penicillium variabile $\mathrm{F} 13$ được cho là có tiềm năng trong cải thiện đất trồng chè bị acid hoá thông qua việc giảm thiểu hàm lượng nhôm linh động trong đất, đảm bảo năng suất cũng như chất lượng của sản phẩm chè.
\end{abstract}

Tù khoá: Đất acid, đất trồng chè, nấm mốc chịu acid, nấm mốc kháng nhôm, hấp thụ nhôm.

\section{1. Đặt vấn đề}

Chè xanh (Camellia sinensis) là loại cây ưa đạm, vì vậy trong quá trình canh tác, một lượng

\footnotetext{
*Tác giả liên hệ. ĐT.: 84-917691012.

Email: ngotuongchau@hus.edu.vn

https://doi.org/10.25073/2588-1094/vnuees.4319
}

lớn phân đạm (đặc biệt là ammonium sulfate) đã được bón vào trong đất trồng chè nhằm tăng hàm lượng amino acid trong lá chè, đồng thời tạo màu sắc hấp dẫn và hương vị đậm đà của sản phẩm chè. Khi cây chè hấp thụ một lượng lớn ammonium, sulfate được tích tụ trong đất. Ngoài ra, ammonium được bón vào đất trồng chè nhanh chóng bị chuyển đổi thành nitrate bởi 
vi khuẩn nitrate hóa tự dưỡng có khả năng chịu acid [1]. Hậu quả là một lượng đáng kể nitrate và sulfate được tích luỹ dần trong đất trồng chè [2], làm pH đất giảm xuống còn 4,0 hoặc thậm chí thấp hơn, từ đó làm tăng hàm lượng nhôm linh động trong đất trồng chè [3]. Trong điều kiện này, cây chè được cho là hấp thụ một lượng nhôm đáng kể, có thể ảnh hưởng trực tiếp đến sức khoẻ của người tiêu dùng (như bệnh yếu thận) [4]. Ngoài ra, hàm lượng nhôm cao trong cơ thể người được giả thuyết là có mối liên quan với nhiều bệnh khác nhau, như chứng mất trí não, xơ não, gãy xương và bệnh Alzheimer [5-7].

Là một thành phần quan trọng của môi trường đất, vi sinh vật đất chắc chắn bị ảnh hưởng bởi độc tính nhôm [8]. Tuy vậy một số vi sinh vật vần có thể tồn tại và phát triển trong điều kiện khắc nghiệt này nhờ các cơ chế kháng và hấp thụ kim loại của chúng. Vì vậy không thể phủ nhận rằng việc phân lập và nghiên cứu đặc tính của vi sinh vật chịu acid và kháng nhôm cao là tiền đề cho biện pháp phục hồi sinh học đất trồng chè. Đến nay, đã có một số chủng vi sinh vật chịu acid và kháng nhôm cao đã được phân lập [9-12]. Trên thực tế, khả năng kháng nhôm của vi sinh vật liên quan chặt chẽ với môi trường sống của nó [12]. Trong nghiên cứu này, chúng tôi báo cáo về khả năng chịu acid, kháng và hấp thụ nhôm của hai chủng nấm mốc Eupenicillium javanicum $\mathrm{F} 8$ và Penicillium variabile F13 phân lập từ đất trồng chè vùng Tân Cương, Thái Nguyên, Việt Nam.

\section{2. Đối tượng và phương pháp nghiên cứu}

\section{1. Đối tượng nghiên cưu}

- Đất trồng chè tại hai thôn Soi Vàng và Hồng Thái, xã Tân Cương, thành phố Thái Nguyên, tỉnh Thái Nguyên. Các mẫu đất thu tại các địa điểm khác nhau với các đặc điểm được trình bày trong bảng 1 .

- Các chủng nấm mốc chịu acid, kháng và hấp thụ nhôm được phân lập từ các mẫu đất nói trên.
Bảng 1. Bảng ký hiệu mẫu đất

\begin{tabular}{ccl}
\hline TT & $\begin{array}{l}\text { Ký hiệu } \\
\text { mấu đất }\end{array}$ & Đặc điểm \\
\hline 1 & MĐ1 & $\begin{array}{l}\text { Là loại đất thịt pha cát được thu từ } \\
\text { vùng đất trồng chè đã canh tác } 30- \\
40 \text { năm tại thôn Soi Vàng. }\end{array}$ \\
2 & MĐ2 & $\begin{array}{l}\text { Là loại đất sỏi cơm được thu từ vùng } \\
\text { đất trồng chè đã canh tác được } \\
\text { năm tại thôn Hồng Thái. }\end{array}$ \\
3 & MĐ3 & $\begin{array}{l}\text { Là loại đất sỏi cơm được thu từ vùng } \\
\text { dất trồng chè đã canh tác được trên } \\
10 \text { năm tại thôn Hồng Thái. }\end{array}$ \\
\hline
\end{tabular}

\subsection{Phuơng pháp nghiên cúu}

Phương pháp thu mẫu và xủ lý mẫu: Mẫu đất được lấy theo phương pháp lấy mẫu hỗn hợp tại tầng mặt có độ sâu $0-20 \mathrm{~cm}$ (TCVN 7538-2:2005). Mỗi mẫu đất hỗn hợp gồm 10 mẫu đất riêng biệt trộn đều với nhau cho đến khi mẫu cuối cùng đạt khối lượng khoảng 1 $\mathrm{kg} / \mathrm{mẫu}$. Mẫu sau khi thu về được rây qua rây 2 $\mathrm{mm}$ để loại bỏ sỏi, đá, xỉ và các tạp chất sau đó được chứa trong túi zip kín, dán nhãn và bảo quản ở $4^{\circ} \mathrm{C}$.

Phương pháp xác định một số tính chất đất: Giá trị $\mathrm{pH}\left(\mathrm{H}_{2} \mathrm{O}\right)$ được xác định bằng máy đo $\mathrm{pH}$ và chiết mẫu với tỉ lệ đất: nước cất là 1:2,5 (theo TCVN 5979:2007). Độ ẩm được xác định bằng phương pháp trọng lượng (theo TCVN 6648:2000). Hàm lượng $\mathrm{C}$ tổng số được xác định theo TCVN 6642-2000. Hàm lượng $\mathrm{N}$ tổng số được xác định bằng phương pháp Kjeldahl (theo TCVN 6498:1999). Hàm lượng nhôm tổng số được xác định bằng phương pháp quang phổ phát xạ nguyên tử (ICP- OES OPTIMA 7300V), phá mẫu theo TCVN 73701:2004. Tổng số vi sinh vật tổng số được xác định bằng phương pháp đếm trên đĩa thạch chứa môi trường thạch- nước thị- peptone (cao thịt $3 \mathrm{~g}$, peptone $10 \mathrm{~g}, \mathrm{NaCl} 15 \mathrm{~g}$, agar $15 \mathrm{~g}$, nước cất $1 \mathrm{~L}, \mathrm{pH} 7,0)$.

Phương pháp phân lập và tuyển chọn nấm mốc chịu acid và kháng nhôm: Các chủng nấm mốc chịu acid và kháng nhôm được phân lập trên các đĩa thạch chứa môi trường Hansen (glucose $50 \mathrm{~g}$, peptone $10 \mathrm{~g}, \mathrm{KH}_{2} \mathrm{PO}_{4} 3 \mathrm{~g}$, 
$\mathrm{MgSO}_{4} .7 \mathrm{H}_{2} \mathrm{O} 3 \mathrm{~g}$, agar $20 \mathrm{~g}$, nước cất $1 \mathrm{~L}$ ), $\mathrm{pH}$ 3,0 , chứa nhôm với nồng độ $100 \mathrm{mgL}^{-1}$ mà đã được chuẩn bị theo phương pháp của Kanazawa và Kunito (1996) [13]. Sau 3 ngày nuôi cấy ở $30^{\circ} \mathrm{C}$, chọn các khuẩn lạc riêng biệt có hình thái đặc trưng, cấy sang các đĩa thạch như trên với các nồng độ nhôm tăng dần $(300,500,700$ $\mathrm{mgL}^{-1}$ ) và tiếp tục nuôi cấy ở điều kiện này. Sau đó, tuyển chọn các chủng nấm mốc có khả năng sinh trưởng và phát triển tốt (đánh giá thông qua kích thước khuẩn lạc) ở nồng độ nhôm cao nhất, cấy truyền sang các ống thạch nghiêng chứa môi trường Hansen để giữ giống.

Phuiơng pháp định danh các chủng nấm mốc: Các chủng nấm mốc được định danh dựa vào các đặc điểm về hình thái (khuẩn lạc và tế bào) và đặc điểm di truyền (trình tự nucleotide của đoạn gen $28 \mathrm{~S}$ rRNA).

Phưong pháp nghiên cúu khả năng chịu acid của cácchủng nấm mốc: Chuẩn bị các bình tam giác thể tích $250 \mathrm{~mL}$ chứa $100 \mathrm{~mL}$ môi trường Hansen dịch thể với nồng độ nhôm 100 ppm, pH được điều chỉnh ở các mức từ 2,2 đến 3,0. Bố trí thêm một bình với $\mathrm{pH} 5,0(\mathrm{pH}$ tối ưu của nấm mốc) để đối chứng. Giống được cấy chuyển từ các ống thạch nghiêng vào các bình, nuôi cấy trên máy lắc ổn nhiệt (New Brunswick, Innova 44R, Eppendorf, Germany) ở $30^{\circ} \mathrm{C}, 150$ vòng/phút. Sau 5 ngày nuôi cấy, ly tâm dịch thể với tốc độ 3.000 vòng/phút trong 15 phút rồi lọc thu sinh khối. Đánh giá khả năng chịu acid của các chủng nấm mốc thông qua sinh khối thu được.

Phương pháp nghiên cúu khả năng hấp thu nhôm của các chủng nấm mốc: Chuẩn bị các bình tam giác thể tích $250 \mathrm{~mL}$ chứa $100 \mathrm{~mL}$ môi trường Hansen dịch thể ( $\mathrm{pH} \mathrm{3,0)}$ với nồng độ nhôm từ 100 đến 2000 ppm. Giống được cấy chuyển từ các ống thạch nghiêng vào các bình, nuôi cấy trên máy lắc ổn nhiệt (New Brunswick, Innova 44R, Eppendorf, Germany) ở $^{3} 30^{\circ} \mathrm{C}, 150$ vòng/phút. Sau 5 ngày nuôi cấy, ly tâm dịch thể với tốc độ 3.000 vòng/phút trong 15 phút, lọc để tách sinh khối và dịch lọc. Dịch qua lọc tiếp tục được qua màng lọc vô trùng có kích thước lỗ $0,25 \mu \mathrm{m}$. Đánh giá khả năng kháng nhôm dựa vào sinh khối thu được và khả năng hấp thụ nhôm dựa vào nồng độ nhôm còn lại trong dịch sau nuôi cấy mà được xác định bằng phương pháp quang phổ phát xạ nguyên tử (ICP- OES OPTIMA 7300V).

\section{Kết quả nghiên cứu và thảo luận}

3.1. Một số tính chất co bản của đất trồng chè vùng Tân Cương, Thái Nguyên

Cây chè được trồng trên đất có giá trị $\mathrm{pH}$ trong khoảng 4,5 - 5,5 được xem là tốt nhất cho việc đồng hoá các chất dinh dưỡng [14]. Ở đây, các mẫu đất có $\mathrm{pH}$ dao động trong khoảng 3,46 - 4,29. Mẫu MĐ1 có giá trị pH thích hợp hơn cho việc trồng chè, trong khi đó các mẫu $\mathrm{MĐ2}$ và MĐ3 có các giá trị $\mathrm{pH}$ tương đối thấp. Bên cạnh đó, các mẫu đất (thu vào tháng $2 / 2018$ ) có độ ẩm trung bình $27,7-28,0 \%$. Đây là khoảng độ ẩm thích hợp cho sự phát triển của cây chè. Ngoài ra, hàm lượng $\mathrm{C}$ tổng số của các mẫu đất dao động trong khoảng $1,07-1,37 \%$ và hàm lượng $\mathrm{N}$ tổng số chênh lệch khá lớn $(0,11-$ $0,3 \%)$. Hàm lượng nhôm tổng số có sự biến động đáng kể giữa các mẫu đất. Số lượng vi sinh vật tổng số của mẫu MĐ2 là cao hơn so với các mẫu đất còn lại. Điều này có thể là do sự khác nhau về loại đất và thời gian canh tác của các mẫu đất nghiên cứu.

Bảng 2. Một số tính chất cơ bản của các mẫu đất nghiên cứu

\begin{tabular}{lllllll}
\hline Ký hiệu mẫu & $\mathrm{pH}\left(\mathrm{H}_{2} \mathrm{O}\right)$ & $\begin{array}{l}\text { Độ ẩm } \\
(\%)\end{array}$ & $\begin{array}{l}\text { Tổng } \mathrm{C} \\
(\%)\end{array}$ & $\begin{array}{l}\text { Tổng } \mathrm{N} \\
(\%)\end{array}$ & $\begin{array}{l}\text { Nhôm tổng số } \\
\left(\mathrm{mgKg}^{-1}\right)\end{array}$ & $\begin{array}{l}\text { Số lượng vi sinh vật } \\
\text { tổng số }\left(\mathrm{CFUg}^{-1}\right)\end{array}$ \\
\hline MĐ1 & 4,3 & 27,7 & 1,37 & 0,20 & 73,5 & $6,30 \times 10^{5}$ \\
MĐ2 & 3,7 & 28,0 & 1,07 & 0,11 & 97,4 & $1,33 \times 10^{7}$ \\
MĐ3 & 3,5 & 28,0 & 1,17 & 0,30 & 38,6 & $1,23 \times 10^{5}$
\end{tabular}




\subsection{Kết quả phân lập và tuyển chọn các chủng} nấm mốc chịu acid và kháng nhôm

Từ các mẫu đất trồng chè vùng Tân Cương, Thái Nguyên, 16 chủng nấm mốc (ký hiệu từ F1 đến F16) có khả năng chịu acid và kháng nhôm đã được phân lập trên môi trường Hansen thạch đĩa $(\mathrm{pH} 3,0)$ chứa nhôm với nồng độ $100 \mathrm{mgL}^{-1}$. Trong đó, hai chủng nấm mốc ký hiệu $\mathrm{F} 8$ và F13 có thể phát triển tốt trên môi trường Hansen thạch đĩa $(\mathrm{pH} 3,0)$ chứa nhôm với nồng độ lên đến $700 \mathrm{mgL}^{-1}$. Trước đấy, Kanazawa và Kunito (1996) cũng đã phân lập được 8 loài nấm mốc từ đất acid có khả năng chịu nhôm với nồng độ $100 \mathrm{mM}$ trên môi trường thạch dinh dưỡng pha loãng 10 lần [13]. Đồng thời, nấm mốc được cho là chiếm ưu thế trong tổng số vi sinh vật chịu acid và kháng $\mathrm{Al}$ được xác định. Điều này có thể là do khả năng chịu acid của nấm mốc thường cao hơn so với vi khuẩn. Vì vậy hai chủng nấm mốc này đã được chọn làm đối tượng cho các nghiên cứu tiếp theo.

\subsection{Kết quả định danh các chủng nấm mốc F8 và $F 13$}

Chủng $\mathrm{F} 8$ có khuẩn lạc màu trắng, mặt dạng nhung và đường kính khoảng 50 mm (Hình 1$)$.
Kết quả phân tích trình tự đoạn gen $28 \mathrm{~S}$ rRNA của chủng $\mathrm{F} 8$ bằng phần mềm Sequecing Analysis 5.3, đồng thời so sánh trình tự này với cơ sở dữ liệu của GenBank và NCBI bằng phần mềm BLAST cho thấy trình tự này tương đồng $100 \%$ với trình tự đoạn gen $28 \mathrm{~S}$ rRNA của chủng Eupenicillium javanicum AFTOL-ID 429 (mã số truy cập EF413621.1). Vì vậy chủng $\mathrm{F} 8$ được xếp vào chi Eupenicillium, loài Eupenicillium javanicum và định danh là Eupenicillium javanicum F8.

Chủng F13 có khuẩn lạc màu xanh xám, tròn đều với các vòng tròn đồng tâm và đường kính khoảng 19 mm (Hình 2). Kết quả phân tích trình tự đoạn gen $28 \mathrm{~S}$ rRNA của chủng F13 bằng phần mềm Sequecing Analysis 5.3, đồng thời so sánh trình tự này với cơ sở dữ liệu của GenBank và NCBI bằng phần mềm BLAST cho thấy trình tự này tương đồng $100 \%$ với trình tự đoạn gen $28 \mathrm{~S}$ rRNA của chủng Penicillium variabile KUC1476 (mã số truy cập HM469398.1). Chủng F13 được xếp vào chi Penicillium, loài Penicillium variabile. Vì vậy, trong nghiên cứu này, chủng $\mathrm{F} 13$ được định danh là chủng Penicillium variabile F13.

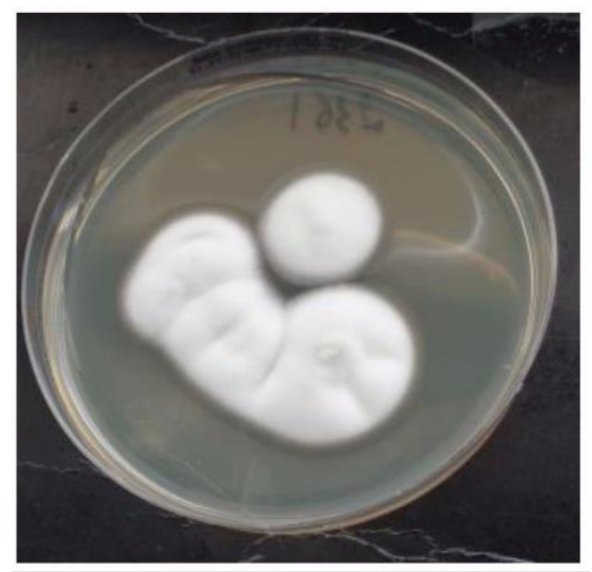

TGAAATTGTTGAAAGGAAGCGCTTGCGACCAGACTCGCTCGCGGGGTTCAGCCG GCCTTCGGGCCGGTGTACTTCCCCGCGGGCGGGCCAGCGTCGGTTTGGGCGGCC GGTCAAAGGCCCTCGGAATGTAACGCCCCCCGGGGCGTCTTATAGCCGAGGGTGC CATGCGGCCAGCCCGGACCGAGGAACGCGCTTCGGCTCGGACGCTGGCATAATGG TCGTAAGCGACCCGTCTTGAAACACGGACCAAGGAGT

Hình 1. Hình thái khuẩn lạc trên đĩa thạch Sabouraud và trình tự gen $28 \mathrm{~S}$ rRNA của chủng F8. 

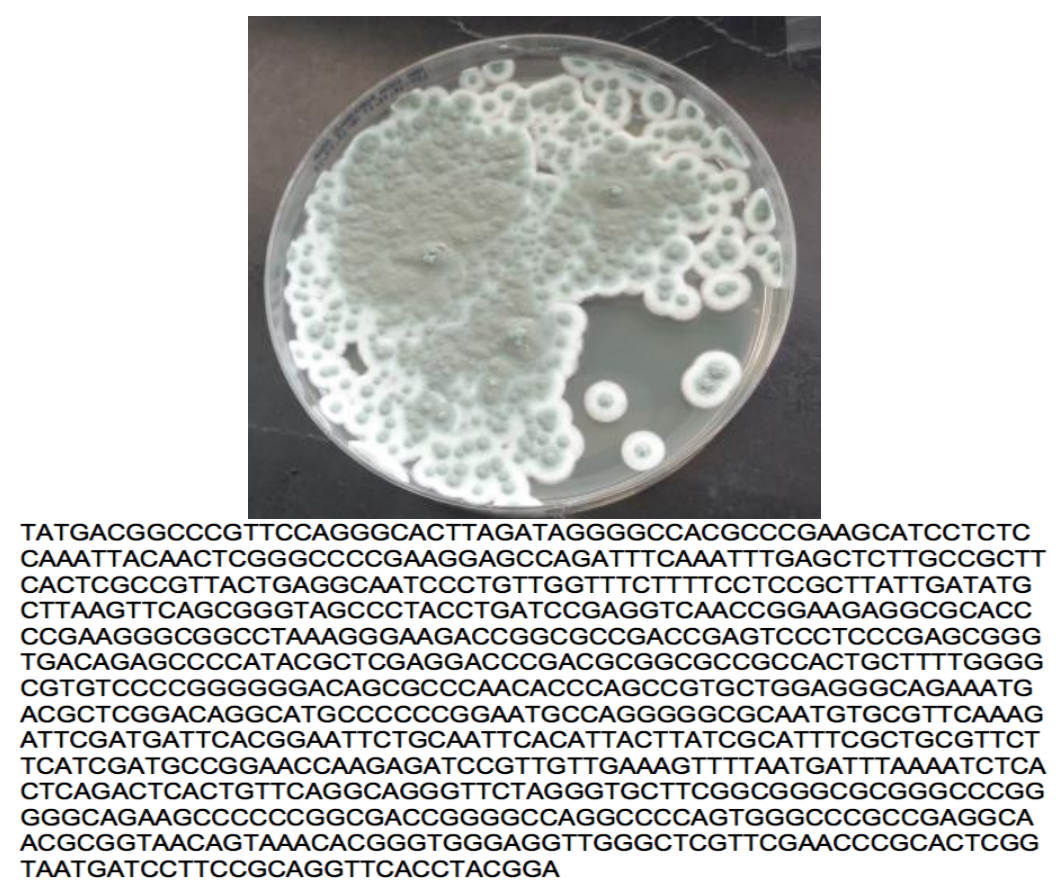

Hình 2. Hình thái khuẩn lạc trên đĩa thạch Sabouraud và trình tự gen $28 \mathrm{~S}$ rRNA của chủng F13

\subsection{Khả năng chịu acid của cácchủng nấm mốc} được tuyển chọn

Cả hai chủng nấm mốc Eupenicillium javanicum $\mathrm{F} 8$ và Penicillium variabile F13 có thể phát triển tốt trong môi trường Hansen dịch thể chứa nhôm với nồng độ $100 \mathrm{mgL}^{-1}$ ở các giá trị pH từ 2,2 đến 5,0 đặc biệt là ở pH 2,4 (Bảng 3 , Hình 3). Trong khi đó, Genhe và cs. (2016) đã xác định được hai chủng $\mathrm{S} 4$ và $\mathrm{S} 7$ có khả năng phát triển trên môi trường chứa nhôm với các giá trị $\mathrm{pH}$ từ 3,20 đến 3,11 [12]. Vì vậy giá trị $\mathrm{pH} 2,4$ này được chọn cho các nghiên cứu tiếp theo.

Bảng 3. Khả năng sinh trưởng và phát triển của các chủng nấm mốc ở 100 các giá trị $\mathrm{pH}$ khác nhau (g sinh khối khô $\mathrm{L}^{-1}$ )

\begin{tabular}{lllllll}
\hline \multirow{2}{*}{ Chủng } & \multicolumn{7}{c}{$\mathrm{pH}$} \\
\cline { 2 - 7 } & 2,2 & 2,4 & 2,6 & 2,8 & 3,0 & 5,0 \\
\hline Eupenicillium javanicum F8 & 9,83 & 13,24 & 8,24 & 7,45 & 7,38 & 9,27 \\
Penicillium variabileF13 & 7,65 & 12,65 & 8,97 & 7,25 & 7,86 & 8,95 \\
\hline
\end{tabular}

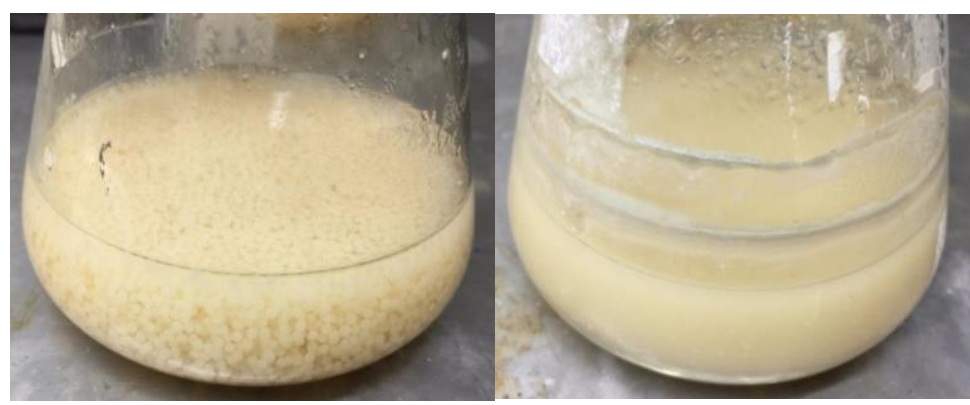

Hình 3. Sinh khối của chủng F13 (trái) và F8 (phải) trong môi trường Hansen dịch thể $\mathrm{pH}=2,4$ 


\subsection{Khả năng sinh truởng, phát triển và hấp thụ nhôm của các chủng nấm mốc}

Sau 5 ngày nuôi cấy trong môi trường Hansen dịch thể chứa các nồng độ nhôm khác nhau $(\mathrm{pH} 2,4)$ trên máy lắc ổn nhiệt tại $30^{\circ} \mathrm{C}$, 150 vòng/phút, sinh khối tạo thành và hiệu suất hấp thụ nhôm của các chủng nấm mốc đã được xác định và thể hiện ở Bảng 4 . Qua đó cho thấy khả năng sinh trưởng và phát triển của các chủng nấm mốc giảm dần khi nồng độ nhôm tăng dần. Tại nồng độ nhôm $2.000 \mathrm{mgL}^{-1}$, sinh khối của chủng $\mathrm{F} 8\left(6,14 \mathrm{gL}^{-1}\right)$ đạt $29,91 \%$ và chủng F13 $\left(5,62 \mathrm{gL}^{-1}\right)$ đạt $31,41 \%$ so với đối chứng (không chứa nhôm) và hiệu suất hấp thụ nhôm của chủng F8 đạt $92,06 \%$ cao hơn so với của chủng $\mathrm{F} 13$ đạt $86,88 \%$. So sánh với kết quả nghiên cứu của Genhe và cs. (2016) khi báo cáo rằng trong môi trường dịch thể với nồng độ 200 nmolL ${ }^{-1}$, chủng $\mathrm{S} 4$ có hiệu suất hấp thụ nhôm đạt gần $85 \%$ và chủng $\mathrm{S} 7$ có hiệu suất hấp thụ nhôm chỉ $27 \%$ so với đối chứng [12] thì các kết quả nghiên cứu của chúng tôi là cao hơn.

Bảng 4. Khả năng sinh trưởng, phát triển và hiệu suất hấp thụ nhôm của các chủng nấm mốc ở các nồng độ nhôm khác nhau

\begin{tabular}{llllllll}
\hline \multirow{2}{*}{ Chủng } & \multirow{2}{*}{ Chỉ tiêu theo dõi } & \multicolumn{5}{c}{ Nồng độ nhôm $\left(\mathrm{mgL}^{-1}\right)$} \\
\cline { 3 - 7 } & Khối lượng sinh khối khô $\left(\mathrm{gL}^{-1}\right)$ & 20,53 & 7,44 & 600 & 1000 & 1500 & 2000 \\
\hline \multirow{2}{*}{ F8 } & Hiệu suất hấp thụ (\%) & 0 & 86,49 & 87,59 & 9,35 & 6,43 & 6,14 \\
& \multirow{2}{*}{ F13 } & Khối lương sinh khối khô $\left(\mathrm{gL}^{-1}\right)$ & 17,89 & 7,32 & 6,48 & 61,38 & 92,06 \\
& Hiệu suất hấp thụ (\%) & 0 & 77,68 & 87,94 & 90,27 & 6,03 & 5,62 \\
& & & & &
\end{tabular}

\section{Kết luận}

Các mẫu đất trồng chè vùng Tân Cương, Thái Nguyên có tính acid cao và hàm lượng nhôm cao. Hai chủng nấm mốc Eupenicillium javanicum F8 và Penicillium variabile F13 được phân lập từ hai trong số các mẫu đất này có khả năng sinh trưởng và phát triển trên môi trường Hansen thạch đĩa $(\mathrm{pH} 3,0)$ có bổ sung nhôm với nồng độ lên đến $700 \mathrm{mgL}^{-1}$. Đồng thời có khả năng sinh trưởng và phát triển tốt trong môi trường Hansen dịch thể (nồng độ nhôm $100 \mathrm{mgL}^{-1}$ ) ở pH 2,2-5,0. Bên cạnh đó, hai chủng nấm mốc này vẫn có thể sinh trưởng và phát triển tại các nồng độ nhôm cao hơn (500-2.000 $\left.\mathrm{mgL}^{-1}\right)$, tuy nhiên lượng sinh khối tạo thành giảm dần khi nồng độ nhôm tăng. Tại nồng độ nhôm $2.000 \mathrm{mgL}^{-1}$, hiệu suất hấp thụ nhôm của chủng F8 (đạt 92,06\%) cao hơn so với của chủng F13 (đạt 86,88\%). Với khả năng chịu acid, kháng và hấp thụ nhôm cao, hai chủng Eupenicillium javanicum $\mathrm{F} 8$ và Penicillium variabile F13 được cho là có tiềm năng trong cải thiện đất trồng chè bị acid hoá nhằm đảm bảo năng suất cũng như và chất lượng của sản phẩm chè.

\section{Tài liệu tham khảo}

[1] M. Hayatsu, Soil microflora and microbial activities in acid tea soils,Bull. Natl. Res. Veg. Ornam. Plants Tea B 6 (1993) 73 (in Japanese).

[2] Nioh, T. Isobe, M. Osada, Microbial biomass and some characteristics of a strongly acid tea field soil, Soil Sci. Plant Nutr. 39 (1993) 617-625.

[3] H Wang, R.K. Xu, N. Wang, X.H. Li, Soil acidification of Alfisols as influenced by tea cultivation in eastern China,Pedosphere 20(6) (2010) 799- 806

[4] M.L. Jackson, P.M. Huang, Aluminum of acid soils in the food chain and senility, Sci. Total Environ. 28(1) (1983) 269-276.

[5] J. Edwardson, Aluminum and the pathogenesis of neurodegenerative disorders, Aluminium Food Environ. 2 (1988) 20-36.

[6] C.N. Martyn, Aluminium and Alzheimer's disease: an epidemiological approach, Environ Geochem. Health 12(1-2) (1990) 169-171.

[7] D. McLachlan, Aluminium and the risk for Alzheimer's disease, Environmetrics 6(3) (1995) 233-275.

[8] P. Illmer, K. Marschall, F. Schinner, Influence of available aluminum on soil-microorganisms, Lett. Appl. Microbiol. 21(1995)393-397. 
[9] F. Kawai, D. Zhang, M. Sugimoto M, Isolation and charac- terization of acid-and Al-tolerant microorganisms. FEMS Microbiol. Lett. 189 (2000) 143-147.

[10] S. Kanazawa, N.T.T. Chau, S. Miyaki S, Identification and characterization of high acid tolerant and aluminum resistant yeasts isolated from tea soils,Soil Sci. Plant Nutr. 51 (2005) 671674.

[11] N.T.T. Chau, L.V. Thien, S. Kanazawa, Identification and characterization of aciditytolerant and aluminum-resistant bacterium isolated from tea soil, African Journal of Biotechnology 13(27) (2014) 2715-2726.
[12] G. He, X. Wang, G. Liao, S. Huang,J. Wu, Isolation, Identification and characterization of two aluminum- tolerant fungi from acidic red soil, Indian J. Microbiol. 56(3) (2016) 344-352.

[13] S.Kanazawa, T. Kunito T, Preparation of pH 3.0 agar plate, enumeration of acid-tolerant and $\mathrm{Al}$ resistant microor- ganisms in acid soils, Soil Sci.Plant Nutr. 42 (1996) 165-173.

[14] A.K.N.Zoysa, A. Anandacoomaraswamy, M.S.D.L.De Silva, Management of soil Fertility in tea lands, Handbook on tea, Tea research institute of Sri Lanka, 2008; pp 27-33.

\title{
Ability to Tolerate Acidity, Resist and Absorb Aluminum of Fungi Isolated from Tea Soils in Tan Cuong, Thai Nguyen, Vietnam
}

\author{
Ngo Thi Tuong Chau ${ }^{1}$, Nguyen Thi Mai Luong ${ }^{2}$, \\ Phung Thi Ngoc Mai ${ }^{1}$, Dao van Huy ${ }^{3}$, Le Van Thien ${ }^{1}$ \\ ${ }^{1}$ Vietnam National University, University of Science, 334 Nguyen Trai, Thanh Xuan, Hanoi, Vietnam \\ ${ }^{2}$ Vietnam National University of Forestry, Xuan Mai, Chuong My, Hanoi, Vietnam \\ ${ }^{3}$ Vietnam National University, Institute of Education Quality Assurance, 144 Xuan Thuy, Hanoi, Vietnam
}

\begin{abstract}
From tea soils in Tan Cuong (Thai Nguyen, Vietnam), 16 acid- tolerant and aluminumresistant fungi were isolated on Hansen plates ( $\mathrm{pH} \mathrm{3.0)}$ with $100 \mathrm{mgL}^{-1} \mathrm{Al}$. Two strains (F8 and F13) could grow wellon Hansen plates $\left(\mathrm{pH} 3.0\right.$ ) with $700 \mathrm{mgL}^{-1}$ Al. Morphological and 28S rDNA sequence analyses indicated that strain F8 belonged to Eupenicillium javanicum, while strain F13 belonged to Penicillium variabile. Further investigation showed that both strains could grow actively in Hansen broth with $100 \mathrm{mgL}^{-1} \mathrm{Al}$ at $\mathrm{pH}$ 2.2- 5.0 and with $500-2,000 \mathrm{mgL}^{-1} \mathrm{Al}$ at $\mathrm{pH}$ 2.4. After 7 days of incubation on a shaker at $30^{\circ} \mathrm{C}, 150 \mathrm{rpm}$, the aluminium absorption efficiency from Hansen broth with $2000 \mathrm{mgL}^{-1} \mathrm{Al}(\mathrm{pH} 2.4$ ) of strain F8 was $92.06 \%$ and that of strain F13 was $86.88 \%$. The fungi areconsidered to be useful not only to improve acidified soils by decreasing the ionic aluminum concentration but also ensure quality of tea product.
\end{abstract}

Keywords: Acid soil, tea soil, acid-tolerant fungi, aluminum-resistant fungi, aluminium absorption. 